\title{
Investigations of the influence of engine thermal state on the fuel consumption of passenger vehicles
}

\begin{abstract}
The paper presents the results of investigations of the fuel consumption of two vehicles performed for non-stabilized engine temperature in the start and warm up phases. The measurements were performed in a wide range of ambient temperatures from-18 ${ }^{\circ} \mathrm{C}$ to $+25^{\circ} \mathrm{C}$. In order to obtain such conditions the tests were carried out in a climate chamber.
\end{abstract}

Key words: passenger vehicle, fuel consumption, engine thermal state

\section{Introduction}

A start-up of a cold engine and its operation in the first moments that follow are a specific state of its operation characterized by, inter alia, increased fuel consumption and exhaust emissions.

A cold start of an engine denotes a state when it operates under the conditions when the temperature of the engine coolant, the lubricating oil and the engine components (including their subassemblies) equals that of the ambient air. In the next stage of the engine operation, the warm up phase of the said components takes place until the optimum operating temperature is reached [1].

The fuel consumption and exhaust emissions upon a cold start depend on the engine thermal state (ambient temperature), the fuel system (diesel spark, ignition), the engine displacement and the exhaust emissions standard.

The fuel consumption and exhaust emissions at cold start become particularly significant if a given routine engine operation involves a high number of starts. The operation of vehicles at cold start predominantly takes place in urban areas and is characterized by an increasing trend of idle operation at very low loads [2]. Literature [3] indicates that up to $45 \%$ of engine starts are cold starts. [1] indicates that in Europe, $50 \%$ of the routes realized in urban areas by passenger vehicles and light-duty trucks (LDV), is shorter than $5 \mathrm{~km}$.

The aim of the research work presented in this paper was to determine the fuel consumption of a combustion engine at cold start and warm up for different ambient temperatures. The warm up process was carried out at minimum loads at idle, which are the least advantageous conditions for quick obtainment of optimum operating conditions. The measurements were performed for two passenger vehicles fitted with engines of different fuel systems (spark ignition and diesel).

\section{Methods of reduction of the fuel consumption of a cold engine}

For a cold engine operating at low loads, an efficient way to reduce the fuel consumption is the reduction of the mechanical resistance or application of solutions providing engine heating prior to its start and accelerating the warm up process of a cold engine during its operation.
Solutions reducing the mechanical resistance of an engine include:

- introduction of design solutions that reduce friction in the piston-crank assembly as well as in the timing system,

- application of low viscosity engine lubricants,

- application of engine aggregates of lower energy consumption, e.g. electrically driven fuel pumps, oil and coolant pumps (or components of variable flow rate) or intelligent charging alternators.

The engine pre-heat and subsequent warm up can be obtained through:

- the application of electric heaters powered from external sources used to heat the oil, or the coolant, or

- the application of electric or combustion-based integrated engine heaters (parking heating).

The application of these solutions requires a supply of a certain amount of electrical energy or fuel, which should be allowed for in the total energy balance. The fundamental reason for applying these systems is to facilitate the engine start at low ambient temperatures as well as improve the thermal comfort in the cockpit immediately after engine ignition.

Solutions that indirectly assist the engine heating process are:

- intelligent blinds preventing the chilling of the engine compartment including the engine itself,

- cooling systems fitted with electronic pumps (during start and warm up, the pump does not operate or works with at reduced flow rate),

- lubrication systems of variable oil capacity in the circuit allowing a reduction of the amount of circulating oil in the phase of engine warm up,

- devices utilizing the exhaust gas energy,

- heat accumulator in the cooling systems that returns the heat accumulated in previous driving cycles.

\section{The test conditions}

The tests have been performed for two passenger vehicles of the below-given characteristics.

LANCIA Ypsilon

- spark ignition engine (SI)

- number of cylinders: 4

- displacement: $1242 \mathrm{~cm}^{3}$

- maximum power/rpm: $51 \mathrm{~kW} / 5500 \mathrm{rpm}$ 
- maximum torque/rpm: $102 \mathrm{Nm} / 3000 \mathrm{rpm}$

- number of valves per cylinder: 2

- turbocharging: no

- fuel system: indirect injection, Multipoint

- emission standard: Euro 6

- lubricating oil: SAE 5W40

- fuel: unleaded gasoline 95.

FIAT Doblo

- diesel engine (CI)

- number of cylinders: 4

- displacement: $1598 \mathrm{~cm}^{3}$

_ maximum power/rpm: $77 \mathrm{~kW} / 4000 \mathrm{rpm}$

- maximum torque/rpm: $290 \mathrm{Nm} / 1500 \mathrm{rpm}$

- number of valves per cylinder: 4

- turbocharging: yes

- fuel system: direct injection, Multijet, common rail

- emission standard: Euro 5

- lubricating oil: SAE 5W30

- fuel: diesel fuel.

The tests were performed in a climate chamber of the Division of Road Tests at Research and Development Institute BOSMAL in Bielsko-Biała. The chamber has the following parameters:

- temperature range: $-45^{\circ} \mathrm{C} \ldots+75^{\circ} \mathrm{C}$

- dimensions: length $870 \mathrm{~cm}$, width $710 \mathrm{~cm}$, height 315 $\mathrm{cm}$.

The fuel consumption measurement was based on the volumetric method utilizing the PLU116H by Pierburg flow meters of the following parameters:

- measurement range: up to $60 \mathrm{l} / \mathrm{h}$,

- measurement accuracy: $\pm 1.5 \%$ of the measured value.

The temperatures of the fluids were measured with the type $\mathrm{K}$ (NiCr-NiAl) thermocouples. Additionally, the basic engine operating parameters were recorded with dedicated diagnostic devices connected to the EOBD port.

The tests were performed for selected ambient temperatures: $-18^{\circ} \mathrm{C},-10^{\circ} \mathrm{C}, 0^{\circ} \mathrm{C},+10^{\circ} \mathrm{C},+25^{\circ} \mathrm{C}$. Prior to each trial the vehicle was conditioned at the required temperature for approx. 24 hours. The criterion for the engine thermal stability was the difference of the engine oil/coolant temperature and the ambient air that was not to exceed $2^{\circ} \mathrm{C}$. The applied fuels had specifications appropriate for the temperature of the trial and the engine oil and coolant were applied as recommended by the manufacturer.

The engine start was performed as recommended by the vehicle manufacturer. For the diesel engine, the glow plug heating procedure was first carried out. Upon start, the engine operated at the minimum idle speed and all additional energy receivers such as heating, air conditioning, lighting etc. were off during the trial. The test ended after 20 minutes from the start (turning on the ignition).

\section{Results}

Figures 1 and 2 present the total amount of consumed fuel [1] after a given time from the engine start for different temperatures.

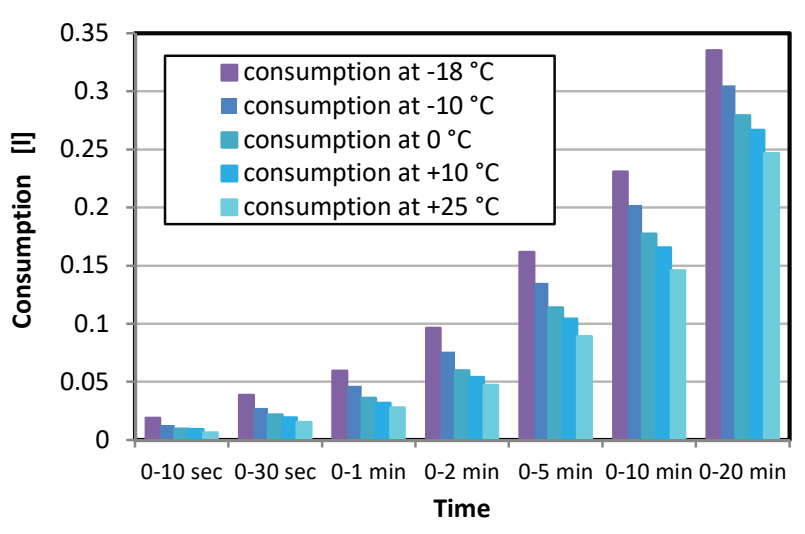

Fig. 1. The amount of fuel consumed by LANCIA Ypsilon (SI)

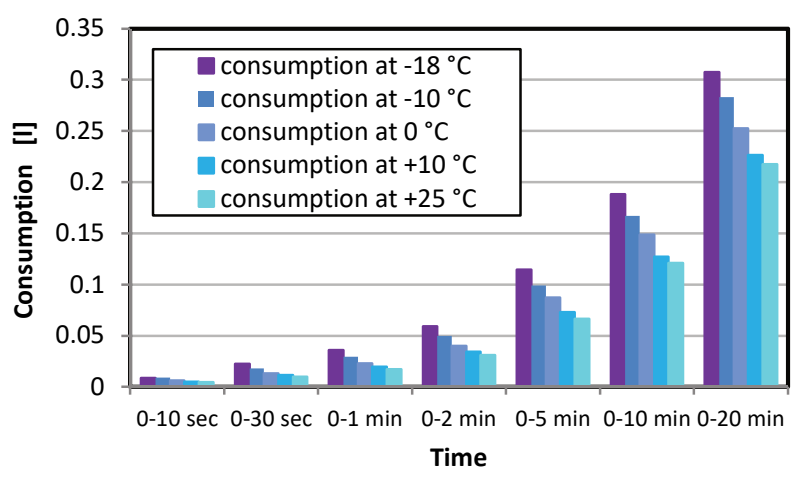

Fig. 2. The amount of fuel consumed by FIAT Doblo (CI)

The Instantaneous fuel consumption $[1 / \mathrm{h}]$ as a function of time for selected temperatures has been shown in Figs 3-5.

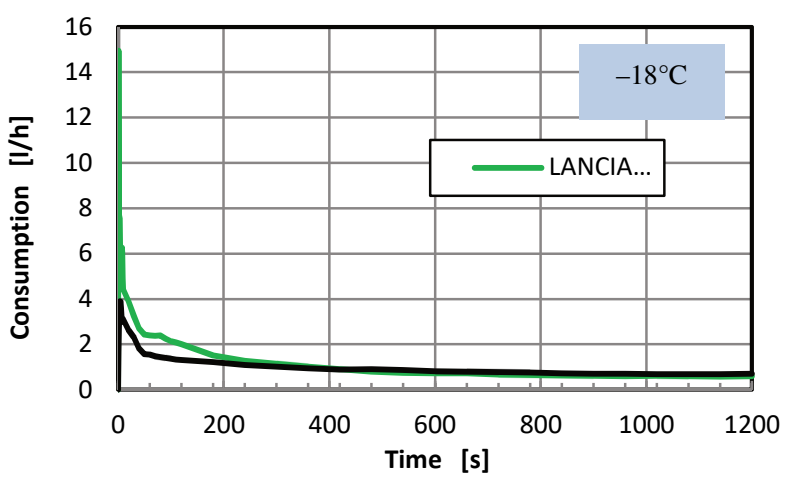

Fig. 3. Instantaneous fuel consumption at the temperature of $-18^{\circ} \mathrm{C}$

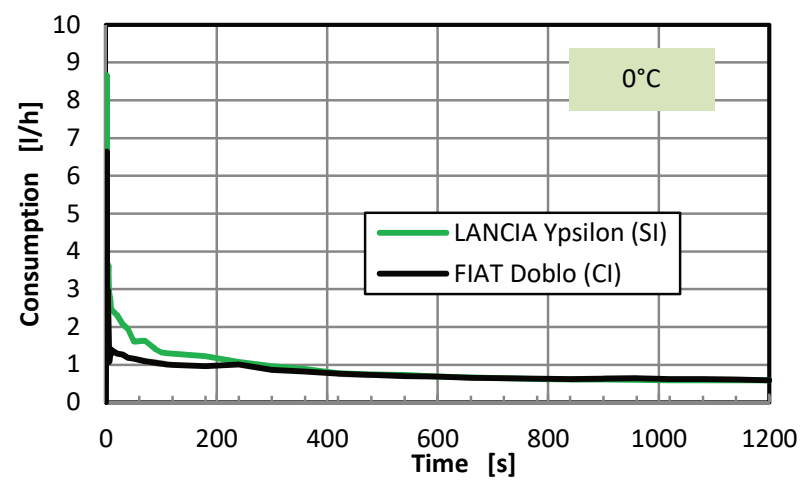

Fig. 4. Instantaneous fuel consumption at the temperature of $0^{\circ} \mathrm{C}$ 


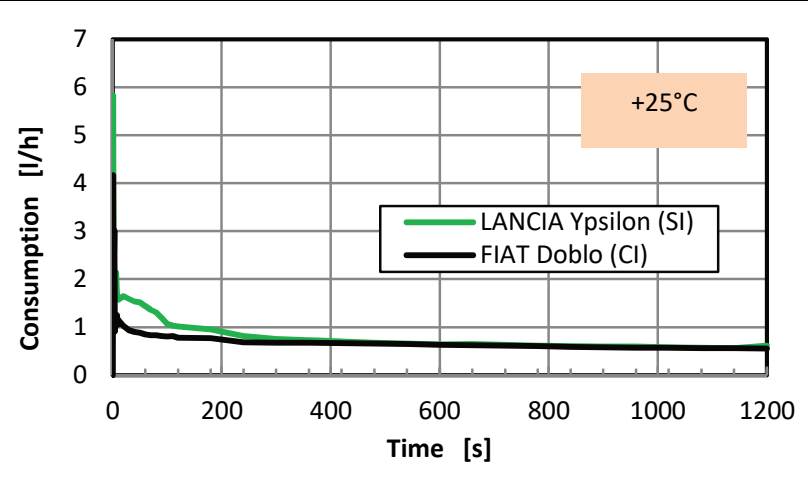

Fig. 5. Instantaneous fuel consumption at the temperature of $+25^{\circ} \mathrm{C}$

For better presentation of the differences in the fuel consumption, Figs 6-8 show the averaged fuel consumption values $[1 / \mathrm{h}]$ in selected time intervals (of different width).

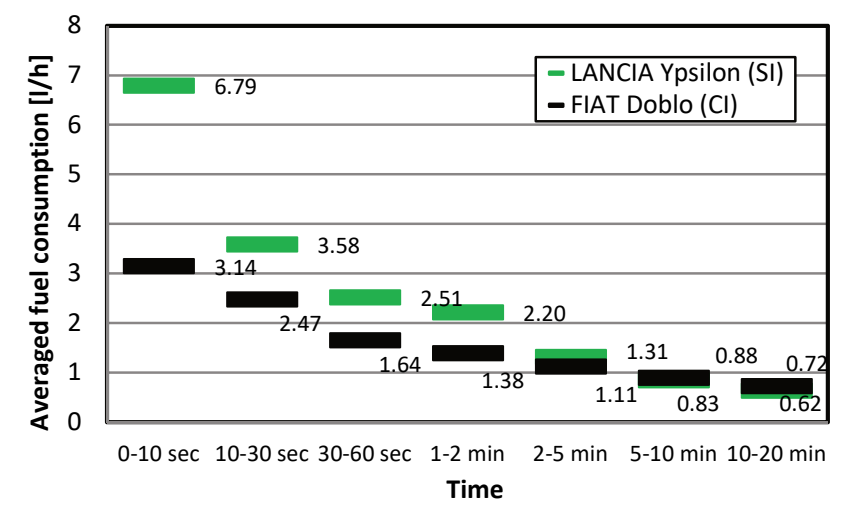

Fig. 6. Averaged fuel consumption at the temperature $-18^{\circ} \mathrm{C}$

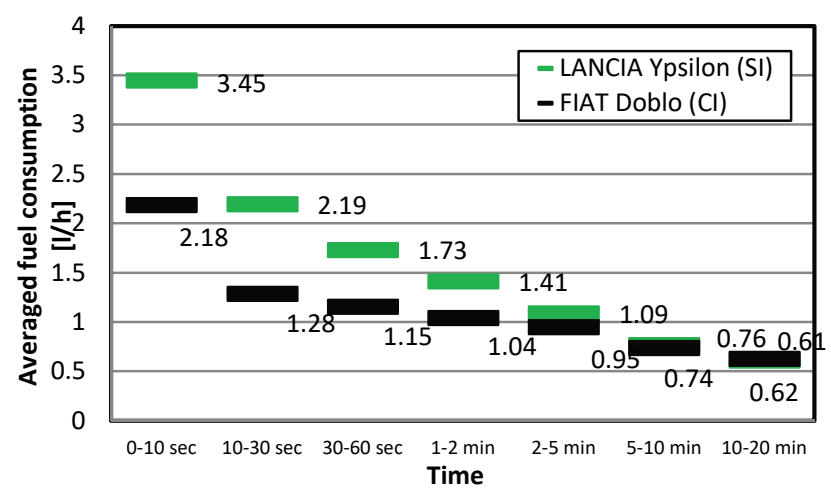

Fig. 7. Averaged fuel consumption at the temperature $0^{\circ} \mathrm{C}$

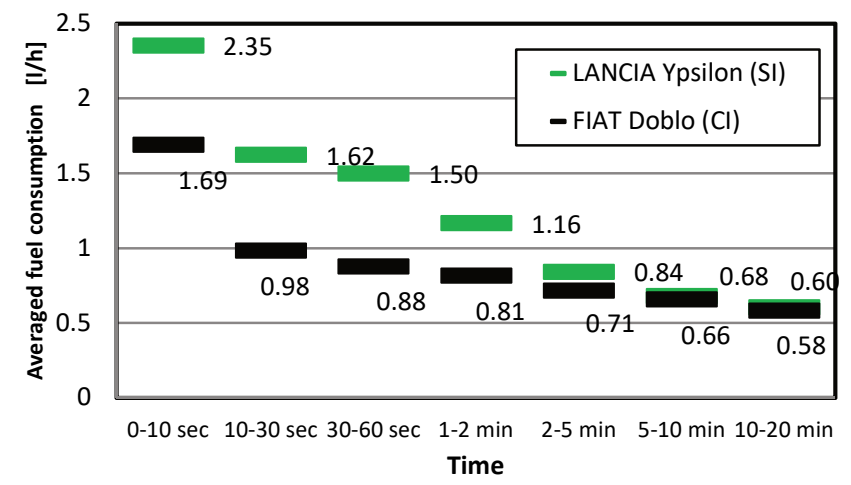

Fig. 8. Averaged fuel consumption at the temperature $+25^{\circ} \mathrm{C}$
The engine warm up during operation at idle is a long process, particularly if diesel engine is the case. The curve of the coolant temperature as a function of time has been shown in Figs 9-11.

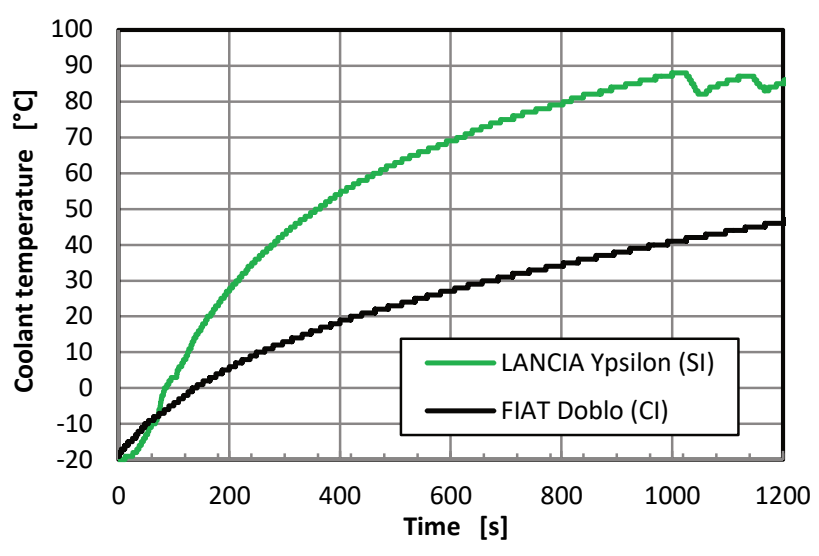

Fig. 9. The coolant temperature at the ambient temperature $-18^{\circ} \mathrm{C}$

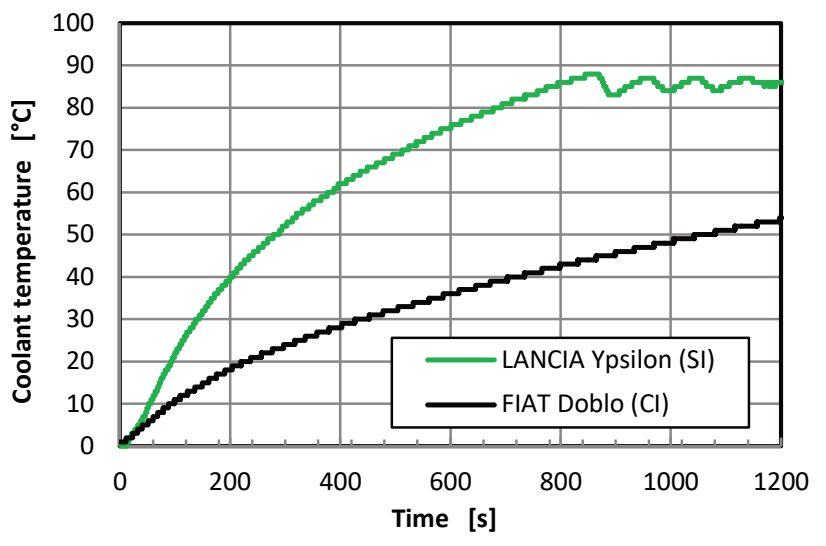

Fig. 10. The coolant temperature at the ambient temperature $0^{\circ} \mathrm{C}$

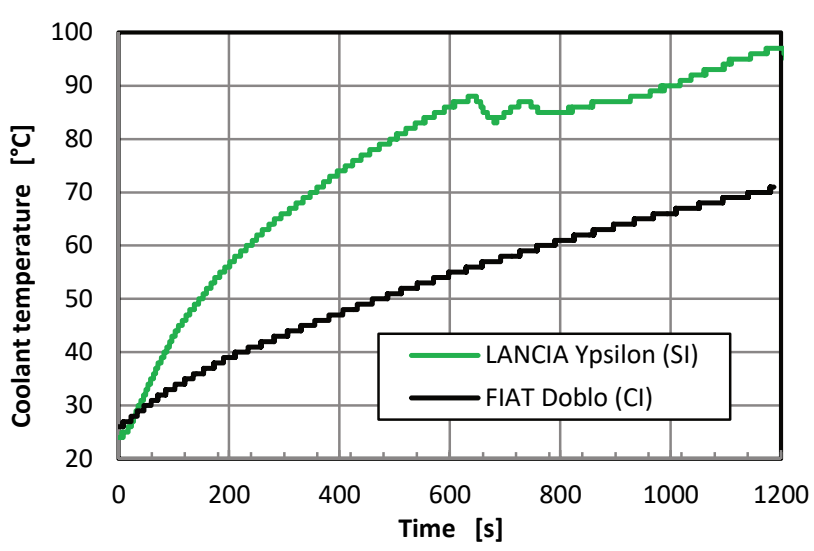

Fig. 11. The coolant temperature at the ambient temperature $+25^{\circ} \mathrm{C}$

\section{Results and discussion}

1. For both tested vehicles (engines) increased fuel consumption has been observed during the engine start and immediately after ignition. Depending on the ambient temperature, already after several seconds, the fuel consumption decreased significantly and asymptotically reached its steady value. 
The increased fuel consumption, particularly under low ambient temperatures, is caused by increased friction inside the engine and unstable combustion e.g. impossibility to form proper air/fuel mixture, misfires, the chilling effect of the combustion chamber walls etc.

2. The influence of the reduced ambient temperature on the fuel consumption in the first phase of engine operation is more conspicuous for spark ignition engines. Comparing the fuel consumption measured in the initial period of 10 seconds after the start of a spark ignition engine in the ambient temperature of $-18^{\circ} \mathrm{C}$ with the fuel consumption of the ambient temperature of $+25^{\circ} \mathrm{C}$, we can observe the it grows three times while for the diesel engine this fuel consumption grows only twice.

In a spark ignition engine, it is necessary to enrich the mixture to evaporate the fuel while filling the cylinder. Besides, in indirect injection systems (as was in the case of the tested engine) increased condensation of vapors occurs on the walls of the intake manifold. The process of mixture enrichment is necessary to quickly reach the readiness of the fuel/air mixture control system to properly activate the closed loop operation based on the signals from the oxygen sensor and to heat up the catalytic converter to its light-off temperature.

When analyzing the results, we need to allow for the differences in the engine displacement of the investigated engines $\left(1242 \mathrm{~cm}^{3}\right.$ spark ignition engine and $1598 \mathrm{~cm}^{3}$ diesel engine).

The engine mechanical resistance is heavily influenced by the temperature and viscosity of the lubricating oil. Oil of the same $5 \mathrm{~W}$ parameter was applied in the investigated engines, characterizing the viscosity under low ambient temperatures. Therefore, when comparing the results, this factor could be omitted.

3. As the engine thermal state stabilizes, the fuel consumption in both engines equalizes. After the start at the temper- ature of $-18^{\circ} \mathrm{C}$, the spark ignition engine stabilizes thermally (reaches the temperature of approx. $+90^{\circ} \mathrm{C}$ ) after the time of approx. 17 minutes while the diesel engine after the same time, reaches only the temperature of $+40^{\circ} \mathrm{C}$.

As described in [4], for the diesel engine, a significant share in the engine mechanical friction is attributed to the drive of the high-pressure injection pump. During idle operation, up to $50 \%$ accumulated mechanical resistance may occur.

\section{Conclusions}

The performed research allowed determining how great the increase of fuel consumption is during the cold start and warm up phases and what the ranges of this value are depending on the ambient temperature. Variable vehicle operating conditions, particularly in the urban cycle make the share of the warm up phase in the entire time of operation increasingly prevalent.

It is recommended that in the further stages of the research, an assessment is carried out of the solutions that may contribute to the reduction of fuel consumption in the warm up phase either through the reduction of engine mechanical resistance or acceleration of the warm-up process. When analyzing the changes in the fuel consumption, it will also be necessary to evaluate the impact of the applied solutions on the exhaust emissions and thermal comfort of the passengers.

A topic of separate analyses (particularly for spark ignition engines) may be the assessment of the applied injection control algorithm (calibration) in terms of air/fuel mixture enrichment in the start and warm-up phases of an engine.

The planned expansion of the BOSMAL climate chamber by a dynamometric roller test bench will enable the performance of tests under conditions close to actual - after the engine start, the engine will warm up in selected driving cycles.

\section{Bibliography}

[1] BIELACZYC, P., MERKISZ, J., PIELECHA, J. Stan cieplny silnika spalinowego a emisja związków szkodliwych. Wydawnictwo Politechniki Poznańskiej. Poznań 2001.

[2] ISKRA, A., KAŁUŻNY, J., BABIAK, M. Charaktery-styka biegu jałowego w fazie nagrzewania silnika. Wydawnictwo Politechniki Krakowskiej. Kraków 2008.

Wojciech Adamski, MEng. - BOSMAL Automotive Research \& Development Institute Ltd in BielskoBiała.

e-mail: Wojciech.Adamski@bosmal.com.pl
[3] JOUMARD, R., ANDRE, M. Cold start emissions of traffic. The Science of the Total Environment. 1990, 93, 175-182.

[4] KARCZEWSKI, M., SZCZĘCH, L. Pomiary oporów wewnętrznych silnika spalinowego. Zeszyty Naukowe Akademii Marynarki Wojennej. 2013, 2(193).

\footnotetext{
Stanisław Polak, Eng. - BOSMAL Automotive Research \& Development Institute Ltd in BielskoBiała.

e-mail: Stanislaw.Polak@bosmal.com.pl
} 